\title{
OBSERVATIONS OF A TRAVELLING MATHEMATICLAN IN EUROPE
}

\author{
H. Schwerdtfeger
}

A travel grant from the National Research Council of Canada enabled me to visit a number of mathematics departments in European universities during the early summer months of 1961. At that time the Summer Semester is still in progress while teaching is at a standstill in our Canadian universities. Moreover six German universities had invited me for a talk in their mathematical colloquium, so I had a good opportunity to talk extensively to professors, lecturers, and senior students.

For about 10 days I stayed in Paris where I visited the Institut Poincaré. Conversations with Favard, and Iater with Kuntzmann, the director of the Institute for Applied Mathematics in the University of Grenoble, gave me some impression of the set-up of mathematical teaching at all levels. It has been thoroughly modernized during the last 15 years! The number of professors seems to have increased in proportion to the number of students. There are good libraries. To provide office space I found that rooms (known to me before the war) had been subdivided. Thus the extension of the department in Grenoble, for example, is not so visible from the outside, although "Applied Mathematics" seems to have been moved into the Engineering Department.

In Germany I saw the mathematics departments of the Universities of Munich, Heidelberg, Frankfurt a. M. , Mainz, Giessen, Marburg, Göttingen, and Hamburg. In most of the se places institute buildings, especially for mathematics, do now exist and extensions a re planned for the near future. Where new buildings are not as yet occupied, as for instance in Göttingen, the existing facilities (the huge Rockefeller Institute) a re considered as too restricted and plans for la rger new buildings have been approved.

More surprising, perhaps, are the plans for increases in the number of professors. I was told that during the next $3-5$ years the number of full professors ("ordentliche Professoren") is to be increased by 55 in West Germany. This includes, of course, those who will be directors of computing centres which exist in almost all universities as on this continent. I noticed that in the University of Mainz (founded only about 12 years ago, because the French wanted in their occupation zone a number of universities comparable to that in the British zone) the re are at present two la rge units in a centre 
with two full proiessors who do research in numerical analysis; the older unit serves only for teaching purposes.

The great number of new appointments to be made seems to worry some of the professors who believe that the re is no adequate number of mathematicians of the required calibre.

The number of students, however, who turn to pure mathematics as their vocation seems to be very large. For my colloquium talk on a very special subject I had always a surprisingly large audience, in some places about $80-100$. It seemed to me that a great number of senior or graduate students attended the colloquium. Personal conversation confirmed my impression that the number of students of mathematics is definitely larger than in Canada.

I often found professors concerned as to that "middle class" of good students who plan to become high-school teachers. Whereas before the war (1939) this used to be a much desired profession in Germany, it seems that too many of these students are attracted into more lucrative positions in industry and computing centres. I found, however, relatively little interest in emigration to nonEuropean countries.

I spent a few days in Holland where I was shown the huge new Mathematics Institute of the Technical University at Delft.

Whatever may be the reasons for the amazing development of mathematics in Europe as on this continent, it is quite obvious that in the European universities the mathematics department has everywhere grown beyond the role of a "service department", it is mathematics for its own sake that is wanted to a degree much higher than ever before.

McGill University, Montreal. 